RESEARCH NOTE

\section{Peridomiciliary Infestation with Triatoma sordida Stal, 1859 in the County of Serra do Ramalho, Bahia, Brazil}

\section{Herton Helder Rocha Pires/ ${ }^{+}$, Érika Carime Borges, Regina Esteves de Andrade*, Elias Seixas Lorosa*, Liléia Diotaiuti}

Laboratório de Biologia de Triatomíneos e Epidemiologia da Doença de Chagas, Centro de Pesquisas René Rachou-Fiocruz, Av. Augusto de Lima 1715, 30190-002 Belo Horizonte, MG, Brasil

*Laboratório de Precipitina, Departamento de Entomologia, Instituto Oswaldo Cruz, Av. Brasil 4365, 21045-900 Rio de Janeiro, RJ, Brasil

Key words: Triatomine - Triatoma sordida - bloodmeal source - control - Bahia - Brazil

Triatoma sordida Stal, 1859 is a predominantly peridomiciliary species that is now the most common triatomine in Brazil (L Diotaiuti et al. 1995 Bol Of Sanit Panam 118: 211-219). Its original habitat was probably the Brazilian "cerrado" (OP Forattini 1980 Rev Saúde Públ 14: 265-99) where it occurs mainly under dead or dry bark of trees (MP Barretto 1979, Epidemiologia, p. 425-449. In Z Brener \& Z Andrade, Trypanosoma cruzi e Doença de Chagas, Guanabara Koogan, Rio de Janeiro, L Diotaiuti et al. 1993 Rev Inst Med Trop São Paulo 35: 237-245). Due to growing the destruction of its original habitat in the last years, as a consequence of new colonization projects and expansion of cultivated areas, resulting in uncontrolled environment interventions, the population densities of this species have risen considerably in environments modified by human activity (OP Forattini et al. 1974 Rev Saúde Públ 8: 265-282), including peridomiciliary ecotopes (Diotaiuti et al. 1995 loc. cit.). Knowledge of the ecology of $T$.

Supported by Fiocruz, FNS, Eclat and sintyal Ind. ${ }^{+}$Corresponding author. Fax: +55-31-295.3115. E-mail: tim@netra.cpqrr.fiocruz.br

Received 5 March 1998

Accepted 3 November 1998 sordida in the peridomicile is an important prerequisite for its control. In order to determine the factors involved in peridomiciliary infestation by this species, a survey of triatomine following spraying with deltamethrin was carried out at domiciliary units (DUs) of Agrovila 12 farm in Serra do Ramalho county, Bahia, Brazil, according to methods already described (L Diotaiuti et al. 1998 Rev Panam Salud Púb 3: 21-25). This area had not been treated with insecticides for four years prior to the study. From the 378 DUs studied, 196 were positive $(51.9 \%)$, with intradomiciliary infestation corresponding to $6 \%$ and the peridomiciliary to $99 \%$. A total of 1,937 insects were captured and the infestation index was reevaluated at 4,8 and 12 months after spraying (Figure). During the pre-intervention survey $48.3 \%$ of the peridomiciliary ecotopes studied were found to be infested, particularly those with wood as the main construction material (constituting $92.1 \%$ of the ecotopes in the survey), where $95.2 \%$ of the insects were captured, followed by those using adobe $(6.2 \%)$, where $3.8 \%$ of the insects were captured and finally those composed of several building materials $(1.8 \%)$, where $1.1 \%$ of the insects were captured. These ecotopes comprised chicken houses $(46.7 \%)$, pigsties $(9.3 \%)$, fences $(33.9 \%)$, bathrooms $(0.9 \%)$ and miscellaneous others $(9.3 \%)$; the proportions of insects collected in each ecotope was 69.3, 5.4, $19.4,0.7$ and $5.2 \%$ respectively (Table I). A total of 2,934 domestic animals were present in the peridomicile at the time of the survey, of which $78.7 \%$ were chickens, $12.5 \%$ pigs, $5.2 \%$ dogs, $3.1 \%$ cats and $0.5 \%$ ungulates (goats or oxen). These animals were present in 82.4, 46.6, 51.5, 28.9 and $1.5 \%$ respectively of the DUs studied. The blood-meal sources identified by the precipitin test were: birds $56.4 \%$, horses $7.2 \%$, rodents $6.7 \%$, human $2.2 \%$, dogs $1.7 \%$, opossum $0.9 \%$, cats $0.1 \%$ and ungulates (goats or oxen) $0.1 \%$. It was not possible to identify the source of $29.2 \%$ of insect blood-meals due to insufficient quantities of blood in the stomach. Double or triple meal sources were identified in 114 triatomines. Of the blood-meals analyzed from insects captured in the intradomicile, 11 were positive for birds, 3 for rodents, 3 for horses, 1 for human and 17 did not react. With respect to insects positive for Trypanosoma cruzi $(0.4 \%), 5$ had ingested bird blood, 4 had ingested horse blood, 1 had ingested rodent blood, 1 bird and horse blood and 6 did not react (Tables II, III). Taking into account that the battery of antisera used probably includes all the main sources of blood available inside the houses, the high proportion $(48.6 \%)$ of insects captured indoors whose blood meals could not be identified could indicate the difficulty with which $T$. sordida adapts to this en- 


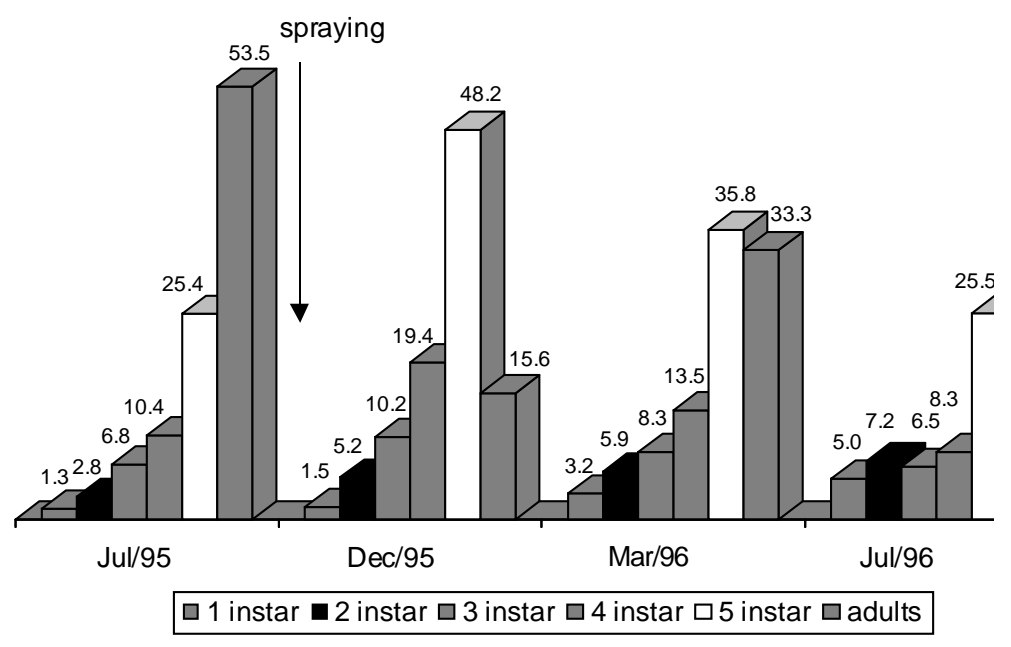

Relative percentage of captured triatomines (Triatoma sordida) in Agrovila 12, Serra do Ramalho, Bahia, according to the instar, at the pre-intervention with pyrethroid and at the post-intervention surveys.

\section{TABLE I}

Number of ecotopes studied in relation to type, construction materials and number of triatomines captured in pre-intervention survey

\begin{tabular}{lrrr}
\hline Ecotope type & No. ecotopes & No. insects captured \\
\hline Chicken house & $106(46.7 \%)$ & $1343(69.3 \%)$ \\
Pigsty & $21(9.3 \%)$ & $104(5.4 \%)$ \\
Fence & $77(33.9 \%)$ & $375(19.4 \%)$ \\
Bathroom & 2 & $(0.9 \%)$ & $14(0.7 \%)$ \\
Other & $21(9.3 \%)$ & $101(5.2 \%)$ \\
\hline Construction material & & & \\
\hline Wood & $209(92.1 \%)$ & $1841(95.2 \%)$ \\
Adobe & $14(6.2 \%)$ & $74(3.8 \%)$ \\
Other (textiles, & $4(1.8 \%)$ & $22(1.1 \%)$ \\
paper, leather) & & & \\
\hline Total & 227 & 1937 \\
\hline
\end{tabular}

vironment and its greater predilection for the peridomicile, where all but $27.8 \%$ of the insects collected did not react against any of the antisera. No correlation was observed between the population density of $T$. sordida during the four surveys and the frequency of positive reactions against human antiserum. Another notable fact is the occurrence of double meal sources involving birds and one mammal species. These associations were observed for all the antisera, and demonstrated the presence of birds in all the ecotopes studied. Chickens comprise practically all of the birds in the study area and other species such as ducks, turkeys, parrots and other ornamental species were rarely encountered. The absence of triatomines inside the houses during the three post-intervention surveys is indicative of the efficacy of pyrethroid insecticides as a control measure. However complete

TABLE II

Overall percentage of triatomine blood meal sources identified by precipitin test in the four infestation surveys

\begin{tabular}{lccccccccc}
\hline Survey & Bird & Human & Dog & Horse & Rodent & Opossum & Cat & Goat/Ox $\begin{array}{c}\text { Not } \\
\text { identified }\end{array}$ \\
\hline 1 & 60.2 & 2.4 & 1.5 & 7.4 & 3.9 & 0.4 & 0 & 0 & 27.2 \\
2 & 64 & 1.3 & 0.6 & 7.5 & 8.1 & 1 & 1 & 0 & 24.4 \\
3 & 47.7 & 2.9 & 4.4 & 5.2 & 12.5 & 3.5 & 0 & 0.9 & 33.4 \\
4 & 31 & 0.5 & 0.5 & 8.9 & 17.3 & 0.5 & 0 & 0 & 45.3 \\
\hline Total & 1375 & 53 & 42 & 176 & 164 & 22 & 3 & 3 & 712 \\
& $(56.4 \%)$ & $(2.2 \%)$ & $(1.7 \%)$ & $(7.2 \%)$ & $(6.7 \%)$ & $(0.9 \%)$ & $(0.1 \%)$ & $(0.1 \%)$ & $(29.2 \%)$ \\
\hline
\end{tabular}


TABLE III

Number of insects reacting to precipitin test which were positive for more than one antisera

\begin{tabular}{|c|c|c|c|c|c|}
\hline Associations & 1st investigation & 2nd investigation & 3rd intervention & 4th intervention & Total \\
\hline \multicolumn{6}{|l|}{ Two antisera } \\
\hline Human/bird & 2 & 1 & 3 & - & 6 \\
\hline Human/dog & - & - & 1 & - & 1 \\
\hline Human/rodent & 1 & - & 1 & - & 2 \\
\hline Bird/dog & 3 & - & 3 & - & 6 \\
\hline Bird/cat & - & 3 & - & - & 3 \\
\hline Bird/horse & 23 & 7 & 5 & 1 & 36 \\
\hline Bird/goat or ox & 2 & - & - & - & 2 \\
\hline Bird/rodent & 12 & 9 & 11 & 3 & 35 \\
\hline Bird/opossum & 1 & 1 & - & - & 2 \\
\hline Dog/horse & 1 & 1 & - & - & 2 \\
\hline Dog/rodent & 2 & - & - & - & 2 \\
\hline Dog/opossum & - & - & 1 & - & 1 \\
\hline Horse/rodent & 3 & 1 & 1 & - & 5 \\
\hline Horse/opossum & - & 1 & - & - & 1 \\
\hline Total & 50 & 24 & 26 & 4 & 104 \\
\hline \multicolumn{6}{|l|}{ Three antisera } \\
\hline Human/bird/dog & - & - & 2 & - & 2 \\
\hline Human/bird/rodent & - & - & 2 & - & 2 \\
\hline Bird/dog/horse & 1 & - & - & - & 1 \\
\hline Bird/dog/rodent & - & - & 1 & - & 1 \\
\hline Bird/horse/rodent & 1 & - & 1 & - & 4 \\
\hline Total & 2 & 0 & 6 & 2 & 10 \\
\hline
\end{tabular}

eradication of triatomines was never achieved in this environment. This can be explained by the rapid degradation of pyrethroid insecticides in outdoor conditions (JCP Dias et al. 1984 Rev Soc Bras Med Trop 14-15) and to the availability of refuges allowing some of the insects to avoid contact with insecticides. This observation is corroborated by comparison of the age structures of the population before and after intervention. One year after spraying, the population of $T$. sordida was equivalent to
$47.8 \%$ of the original number captured, even though large, although the true population size may be much larger if the insects were not removed from the peridomicile during each survey. Nevertheless, the characteristics of the recolonization by $T$. sordida and the time required for the population to regain its original level confirm that a single annual spraying intervention is enough to control this species, as proposed by Diotaiuti et al. 1998 (loc. cit.). 
Peridomiciliary Infestation by T. sordida - Herton HR Pires et al. 